\title{
Desempenho de forrageiras hibernais sob distintos níveis de luminosidade
}

\author{
Roque Kirchner ${ }^{1}$, André Brugnara Soares ${ }^{1}$, Laércio Ricardo Sartor ${ }^{1}$, Paulo Fernando Adami ${ }^{1}$, \\ Francisco Migliorini ${ }^{2}$, Lidiane Fonseca ${ }^{2}$
}

\footnotetext{
1 Programa de pós-graduação em Agronomia - UTFPR - Pato Branco.

2 Curso de Agronomia da UTFPR - Pato Branco.
}

RESUMO - Objetivou-se determinar os possíveis efeitos da restrição de luminosidade, obtida com distintas densidades de árvores de Pinnus taeda, sobre a produção e qualidade de: aveia-preta (Avena strigosa Schreb) cv. Comum, aveia-branca (Avena sativa L.) cv. Fapa 2, azevém (Lolium multiflorum L.) cv. Comum, trigo (Triticum aestivum L.) duplo propósito cv. BRS Tarumã e ervilhaca peluda (Vicia villosa L.). Avaliaram-se três níveis de luminosidade: a sol aberto (sem presença de árvores de Pinnus taeda), 30\% de restrição de radiação (usando espaçamento entre árvores de $15 \times 3$ m, com 222 árvores/ha) e $60 \%$ de restrição de radiação (usando espaçamento de $9 \times 3 \mathrm{~m}$, com 370 árvores/ha). Foram realizadas avaliações da produção de forragem, da composição química e dos componentes estruturais das plantas, do potencial hídrico das plantas, da umidade do solo, das variáveis microclimáticas e da produção de acículas. O delineamento experimental foi de blocos completos ao acaso, em parcelas subdivididas e três repetições. O azevém foi a espécie mais produtiva em todos os níveis de luminosidade, embora a ervilhaca tenha apresentado a menor redução de produção quando sombreada. Houve maior potencial hídrico nas plantas e maior umidade no solo nos ambientes sombreados, mesmo assim, a produção de forragem reduziu significativamente no sombreamento mais intenso (81\%). A composição química e os componentes estruturais de todas as forrageiras estudadas também são afetados pelo aumento da restrição luminosa.

Palavras-chave: composição química, matéria seca, sistema silvipastoril, sombreamento

\section{Performance of hibernal forages under distinct brightness levels}

\begin{abstract}
Possible effects of brightness restriction, obtained by different Pinnus taeda tree densities, on the production and quality of black oat (Avena strigosa Schreb) cv. Common, white oat (Avena sativa L.) cv. FAPA 2, annual ryegrass (Lolium multiflorum L.) cv. Common, hairy vetch (Vicia villosa), wheat (Triticum aestivum L.) cv. dual purpose BRS Tarumã were studied. It was evaluated three brightness levels: 1 - full sunlight with no trees; 2 - 30\% of radiation restriction, using $15 \times 3 \mathrm{~m}$ spacing between trees (222 trees/ha), and; $3-60 \%$ of radiation restriction, using $9 \times 3 \mathrm{~m}$ between trees (370 trees/ha). It was performed evaluations of forage production, chemical composition and structural component of plants, water potential of the plants, soil moisture, microclimate variables and production of needles. The experimental design was completely randomized blocks, in split-plots and three replicates. Ryegrass was the most productive species at all brightness levels, although hairy vetch showed the lowest reduction on production under shading. There was higher water potential in the plants and higher soil moisture under shading, however, forage production was significantly reduced in the most intense shading (81\%). Chemical composition and structural components of all studied forage species are also affected by brightness restriction increase.
\end{abstract}

Key Words: chemical composition, dry mater, shading, silvopasture system

\section{Introdução}

O agronegócio, ao longo das cadeias produtivas, seja ela de origem vegetal ou animal, envolve muitos fatores bióticos e abióticos, desde antes da porteira até o consumidor final. Atualmente discute-se muito a integração das atividades com o argumento de agregação de valor e sustentabilidade. Este é um dos objetivos do sistema agroflorestal, do qual deriva o silvipastoralismo, que proporciona agregação de valor através da produção de madeira para médio e longo prazos e produtos pecuários, em curto prazo.

Para produção animal e de madeira (sistema silvipastoril) faz-se necessário conhecer espécies, tanto do componente do estrato superior como do inferior, e suas interações. Exemplos dessa sinergia seria a melhoria das condições microclimáticas 
para a produção forrageira (Silva et al., 1998), aumento no valor nutritivo da pastagem (Paciullo et al., 2007), bem como a fixação de nitrogênio pela pastagem e possível melhoria da disponibilidade de nitrogênio às arvores (Andrade et al., 2003) ou vice-versa (Castilhos et al., 2003). Apesar das possíveis vantagens, é compreensível a indagação: quanto diminui a produção de forragem quando a pastagem for parcialmente sombreada? Tolerância ao sombreamento é a capacidade de não diminuir, ou diminuir pouco a produção de forragem em relação à produção que teria a pleno sol. Existem diversos trabalhos no Brasil determinando a tolerância ao sombreamento e outras variáveis de espécies forrageiras tropicais (Garcia et al., 2005), no entanto, para as regiões mais frias do sul do Brasil, especialmente no período de inverno, quando a temperatura e radiação são menores, ainda existe a necessidade de informações.

O crescimento da vegetação depende da interceptação da radiação fotossinteticamente ativa (RFA) pelo dossel, da eficiência de uso desta radiação interceptada e da partição de assimilados. Desses processos, a interceptação da RFA é dependente, em grande parte, do índice da área foliar (IAF) do dossel (Difante \& Nascimento Junior, 2003). A limitação da radiação atua de formas diferentes para cada genótipo, principalmente sobre o desenvolvimento e diferenciação do órgão assimilador (cloroplastos). Desta adaptação resultam mudanças das características morfológicas, histológicas e bioquímicas, as quais condicionam um ganho menor de carbono pela planta (Larcher, 2000).

Neste contexto, objetivou-se determinar a tolerância ao sombreamento parcial e natural de Pinus taeda L sobre cinco espécies forrageiras de ciclo hibernal, cultivadas sob três níveis de intensidade luminosa.

\section{Material e Métodos}

O trabalho foi desenvolvido de 21 de abril de 2007, com o preparo do local, a 31 de outubro de 2007, em uma área de plantação Pinus taeda de 14 anos de idade e 14 m de altura. A área experimental, inicialmente apresentava um espaçamento de três metros entre fileiras e três metros entre árvores (espaçamento comercial), quando foram retiradas duas ou três filas, para estabelecer os espaçamentos $9 \times 3$ (370 árvores por hectare) e $15 \times 3$ (220 árvores por hectare), respectivamente em sentido leste/oeste. Além destas, uma área sem árvores, localizada próximo, foi usada para as parcelas a céu aberto (pleno sol). Segundo o sistema brasileiro de classificação de solos (EMBRAPA, 1999), o solo da área experimental é classificado como Latossolo Vermelho Distroférrico Argiloso. O clima, conforme classificação de Köppen (Moreno, 1961) é Cfa, subtropical úmido, sem estação seca e verão ameno. A média das temperaturas máximas e mínimas é de $23,4^{\circ} \mathrm{C}$ e $13,7^{\circ} \mathrm{C}$, respectivamente. Foram colhidas informações microclimáticas, no local do experimento, através da estação de micro-meteorologia móvel, no período 13 a 24 de julho de 2006 e 20/03/2007 a 03/04/2007 (Tabela 01).

Para análise, amostras de solo foram coletadas de 0 a $20 \mathrm{~cm}$ de profundidade, antes e depois de instalar o experimento. A acidez do solo foi corrigida levando em consideração a análise de solo para elevar a saturação de bases a 70\%, usando calcário dolomítico. Da mesma forma, as adubações seguiram as recomendações da Comissão de Fertilidade do Solo para os estados do Rio Grande do Sul e Santa Catarina (2004). Os valores médios, na área com árvores, do nível de $9 \times 3$ m foram: $\mathrm{pH}-\mathrm{H}_{2} \mathrm{O}$ : 5,4; índice SMP: 6,0; P: 6,94 mg/dm ${ }^{3}$; $\mathrm{K}: 0,57 \mathrm{cmol} / \mathrm{dm}^{3}$; MO: 55,4 g/ $/ \mathrm{dm}^{3}$, Al: 0,01 cmol $/ \mathrm{dm}^{3}$; Ca: $5,5 \mathrm{cmol} / \mathrm{dm}^{3}$; Mg: 4,6 cmol $/ \mathrm{dm}^{3} ; 66 \%$ de saturação de bases e 0,2\% de saturação por alumínio. Na área do nível $15 \times 3 \mathrm{~m}$ os valores foram: $\mathrm{pH}-\mathrm{H}_{2} \mathrm{O}: 5,9$; Índice SMP: 6,4; $\mathrm{P}: 7,4 \mathrm{mg} / \mathrm{dm}^{3}$; $\mathrm{K}: 0,56 \mathrm{cmol} / \mathrm{dm}^{3}$; MO: $49 \mathrm{~g} / \mathrm{dm}^{3} ; \mathrm{Al}: 0,09 \mathrm{cmol} / \mathrm{dm}^{3} ; \mathrm{Ca}:$ 5,5 cmol/dm³ ; Mg: 4,17 cmol/ $/ \mathrm{dm}^{3} ; 71 \%$ de saturação de bases e $0,2 \%$ de saturação por alumínio. Na área a céu aberto, a análise de solo apresentou os seguintes teores: pH- $\mathrm{H}_{2} \mathrm{O}: 5,3 ;$ índice SMP: 6,1; P: $15,0 \mathrm{mg} / \mathrm{dm}^{3} ; \mathrm{K}: 0,9 \mathrm{cmol} / \mathrm{dm}^{3}$; MO: $41,5 \mathrm{~g} / \mathrm{dm}^{3}, \mathrm{Al}$ 0,03 cmol $/ \mathrm{dm}^{3}$, Ca: $8,40 \mathrm{cmol} / \mathrm{dm}^{3} ; \mathrm{Mg}$ : $3,3 \mathrm{cmol} / \mathrm{dm}^{3} ; 72 \%$ de saturação de bases e $0,3 \%$ de saturação por alumínio.

Os tratamentos consistiram de três níveis de luminosidade (sombreamentos) caracterizados por duas densidades de árvores (uma densidade de $9 \mathrm{~m}$ de espaçamento entre linhas de Pinus taeda e $3 \mathrm{~m}$ na linha de árvores $(9 \times 3 \mathrm{~m})$ e, a outra de $15 \mathrm{~m}$ entre linhas e $3 \mathrm{~m}$ na linha $(15 \times 3 \mathrm{~m}))$ e um nível a céu aberto (sem sombreamento) e cinco espécies forrageiras anuais de inverno.

Para implantação das forrageiras, a área foi previamente preparada, por meio de roçada e capina manual. A semeadura foi feita no dia 21 de abril de 2007, a lanço e incorporadas manualmente com o uso de enxada. A densidade de semeadura foi de 400 e 320 sementes $/ \mathrm{m}^{2}$ para as aveias e trigo duplo propósito, respectivamente. A profundidade de semeadura foi de dois a quatro $\mathrm{cm}$. Para o azevém foi usada densidade de semeadura de 450 sementes $/ \mathrm{m}^{2}$ incorporadas a um cm de profundidade. A ervilhaca foi estabelecida com 150 sementes $/ \mathrm{m}^{2}$. Nas gramíneas foram utilizados $100 \mathrm{~kg} / \mathrm{ha}$ de nitrogênio em cobertura na forma de ureia, em quatro aplicações, a primeira aos 35 dias após emergência e as três restantes a cada 40 dias até atingir a quantidade total. Todos os procedimentos foram realizados de forma manual. A contagem de plantas após a emergência total, foi feita com retângulo amostral de $20 \times 16$ cm e extrapolado para número 
de plantas $/ \mathrm{m}^{2}$. A medição de altura foi feita com auxílio de um bastão graduado (Sward Stick) conforme descrito por Bircham (1981). Para definição do momento do corte, foram estipuladas alturas, de $30 \mathrm{~cm}$ para as aveias, trigo e azevém e $45 \mathrm{~cm}$ para a ervilhaca. A altura do corte, para as gramíneas, foi sete e dez $\mathrm{cm}$ do solo para azevém e aveias/trigo, respectivamente, e a $15 \mathrm{~cm}$ para ervilhaca peluda.

A umidade do solo foi avaliada por meio de coletas de três pontos nas três condições de luminosidade nas entrelinhas das áreas sombreadas. Para a avaliação do potencial hídrico ( $\psi \mathrm{w}$ ) usaram-se as espécies ervilhaca peluda (estudada no presente trabalho) e trevo branco que, embora não tenha sido incluído neste ensaio, foi usado como objeto de avaliação apenas desta variável, nos três níveis de luminosidade. Utilizou-se a câmara de pressão de Scholander, usando o pecíolo da folha. A primeira avaliação foi realizada às 6 h e a segunda às $12 \mathrm{~h}$, no dia 23 de agosto de 2007.

A produção de forragem foi avaliada entre junho e outubro de 2007, cortando-se amostras com quadro de $0,25 \mathrm{~m}^{2}$ obtido no meio da entrelinha no caso das parcelas sombreadas. O material depois de seco em estufa de ventilação forçada a $55^{\circ} \mathrm{C}$, foi pesado em balança de precisão (0,01 g). Os dados foram extrapolados para produção da forrageira em $\mathrm{kg}$ MS/ha. As parcelas inteiras foram roçadas com roçadeira costal na mesma altura dos cortes amostrais. A produção total de matéria seca por espécie e por hectare (kg MS/ha) foi obtida pela soma de todos os cortes, individualmente para cada repetição. As amostras para determinação da participação dos componentes estruturais foram obtidas pelo corte de um quadro de $20 \times 16 \mathrm{~cm}$, feito na mesma altura do corte, nas datas de avaliação da produção de matéria seca. A participação dos componentes estruturais da pastagem foi obtida pela separação manual da amostra coletada em lâmina foliar e colmo (colmo verdadeiro e bainhas foliares - pseudocolmo). Posteriormente, o material foi seco em estufa de ventilação forçada a $55^{\circ} \mathrm{C}$ e pesado. A divisão do peso obtido das lâminas foliares pelo peso dos colmos resultou no valor da relação lâmina:colmo.

Parte das amostras da planta inteira foi triturada em moinho tipo Willey, acondicionada em embalagens plásticas identificadas e enviadas, ao laboratório para determinação do percentual dos componentes químicos: proteína bruta (PB), fibra em detergente neutro (FDN), pelo método de espectrometria de refletância no infravermelho proximal (NIRS). As amostras foram analisadas separadamente, por espécie, repetição, data e nível de luminosidade.

A produção de matéria seca de acículas foi avaliada através da coleta de amostras em três locais de 0,25 $\mathrm{m}^{2}$, demarcados no início do experimento nas entrelinhas das árvores. A produção foi registrada no final do experimento, nos dois níveis de luminosidade $(9 \times 3$ e $15 \times 3 \mathrm{~m})$, pela coleta manual das acículas depositadas.

O delineamento experimental foi em blocos ao acaso em parcelas subdivididas, com três repetições, de modo que as parcelas principais foram as três condições luminosas (a céu aberto e com 30 ou $60 \%$ de restrição da radiação) e as subparcelas, as cinco espécies forrageiras, num esquema fatorial $3 \times 5$, composto de três níveis de restrição da radiação - 0, 30 e $60 \%$, obtidos por meio de dois espaçamentos entre plantas: $9 \times 3 \mathrm{~m}$ ou $15 \times 3 \mathrm{~m}$ - e cinco forrageiras - aveia-preta (Avena strigosa schreb) cv. comum; aveia-branca (Avena sativa L) cv. Fapa 2; azevém (Lolium multiflorum L) cv. Comum; trigo (Triticum aestivum L) duplo propósito cv. BRS Tarumã; e ervilhaca peluda (Vicia villosa).

As dimensões das parcelas experimentais foram de $15 \mathrm{~m}^{2}$ a pleno sol, $45 \mathrm{~m}^{2}$ no espaçamento $15 \times 3$, e $27 \mathrm{~m}^{2}$ no espaçamento $9 \times 3$. Foram implantadas três repetições para cada espécie forrageira nos três níveis de luminosidade (parcelas).

As variáveis foram submetidas à análise de variância e, quando detectada interação significativa entre os dois fatores, foi feito teste Tukey a 5\% de significância, comparando os níveis de um fator, dentro de um nível do outro fator e vice-versa.

\section{Resultados e Discussão}

As temperaturas médias no local do experimento (Tabela 1) no mês de julho de 2006 encontram-se dentro dos limites em todos os níveis de restrição luminosa adequados para produção de forrageiras de ciclo hibernal. A temperatura do ar, na média dos dois períodos avaliados, foi maior nas parcelas com sombreamento que naquela a céu aberto em 1,05 e $0,75^{\circ} \mathrm{C}$ no espaçamento $15 \times 3$ e $9 \times 3 \mathrm{~m}$, respectivamente. A velocidade do vento diminuiu $47 \%$ e $58 \%$; a radiação total incidente, 48 e $88 \%$; a radiação fotossinteticamente ativa, 48,5 e 71,5\%; a temperatura do solo, 1,2 e $1,7^{\circ} \mathrm{C}$; e a umidade relativa média do ar diminuiu 6 e 0,75 ponto percentual nas parcelas de $15 \times 3$ e $9 \times 3$, respectivamente, em relação àquelas a céu aberto. A umidade do solo aumentou, em relação ao céu aberto, em 5,7 e 4,1 pontos percentuais, nos espaçamentos $15 \times 3$ e $9 \times 3$, respectivamente.

Silva et al. (1998) constataram que a presença da espécie arbórea Grevillea robusta em pastagens da região noroeste do Paraná teve influência sobre algumas variáveis microclimáticas, como a temperatura e a umidade do ar, e sobre a pressão de vapor d'água. A modificação do 
Tabela 1 - Variáveis microclimáticas e umidade do solo em três níveis de luminosidade na região de Abelardo Luz, Santa Catarina

\begin{tabular}{|c|c|c|c|c|c|c|}
\hline \multirow[t]{3}{*}{ Variável microclimática } & \multicolumn{6}{|c|}{ Nível de sombreamento } \\
\hline & \multicolumn{2}{|c|}{ A céu aberto } & \multicolumn{2}{|c|}{$15 \times 3 \mathrm{~m}$} & \multicolumn{2}{|c|}{$9 \times 3 \mathrm{~m}$} \\
\hline & Julho/2006 & Março-abril/ 2007 & Julho/2006 & Março-abril/2007 & Julho/2006 & Março abril/2007 \\
\hline Temperatura média $\left({ }^{\circ} \mathrm{C}\right)$ & $15,3(100)$ & $21,2(100)$ & $16,5(107)$ & $22,1(104)$ & $16,4(107)$ & 21,6 (101) \\
\hline Velocidade máxima do vento $(\mathrm{m} / \mathrm{s})$ & $6,4(100)$ & $1,81(100)$ & $2,9(45)$ & $1,11(61)$ & $2,7(42)$ & $0,76(42)$ \\
\hline Total radiação global (MJ/m²/dia) & $10,8(100)$ & $18,84(100)$ & $6,5(60)$ & $8,25(44)$ & $1,1(10)$ & $2,70(14)$ \\
\hline Radiação fotossintética ativa $\left(\mathrm{MJ} / \mathrm{m}^{2} / \mathrm{dia}\right)$ & $5,3(100)$ & $6,34(100)$ & $3,7(70)$ & $2,10(33)$ & $1,1(40)$ & $1,08(17)$ \\
\hline Temperatura do solo $\left({ }^{\circ} \mathrm{C}\right)$ & $15,9(100)$ & $24,3(100)$ & $16,0(100)$ & $21,9(90)$ & $15,2(96)$ & 21,7 (89) \\
\hline Umidade relativa do ar (\%) & $74,7(100)$ & $78,4(100)$ & 65,5 (88) & $75,5(96)$ & 70,6 (95) & 80,9 (103) \\
\hline Umidade do solo (\%) & & $21,5 b(100)$ & & $27,2 \mathrm{a}(126)$ & & 25,6а (119) \\
\hline
\end{tabular}

Médias seguidas de letras minúsculas diferentes nas linhas diferem $(\mathrm{P}<0,05)$ pelo teste Tukey.

microclima na presença do componente arbóreo repercute sobre o balanço hídrico do solo, contribuindo para a elevação da umidade disponível, além da diminuição da radiação fotossintética e da velocidade do vento, reduzindo assim a evapotranspiração das plantas.

De acordo com a análise de variância, houve interação significativa entre espécies e níveis de luminosidade $(\mathrm{P}=0,0009)$ para a produção de forragem (Tabela 2). $\mathrm{O}$ sombreamento diminuiu significativamente a produção de forragem de todas as espécies forrageiras, especialmente no menor espaçamento arbóreo. A produção média das espécies a céu aberto foi de $6.095 \mathrm{~kg}$ MS/ha, enquanto no espaçamento de $15 \times 3$ m (30\% de restrição de radiação), foi de $2.595 \mathrm{~kg} /$ ha e, no de $9 \times 3 \mathrm{~m}$ ( $60 \%$ de restrição de radiação), $1.150 \mathrm{~kg} / \mathrm{ha}$. Esses resultados confirmam o efeito negativo da restrição de irradiância, apesar das melhores condições de temperatura, umidade, ventos e outros indicadores.

Entre as espécies, também ocorreram diferenças significativas. A céu aberto, o azevém foi a espécie que mais produziu (8.191 kg de MS/ha), mas não diferiu $(\mathrm{P}>0,05)$ da aveia-branca (7.415 kg de MS/ha). As espécies que menos produziram foram trigo duplo propósito (5.147 kg de MS/ha), aveia-preta (4.550 kg de MS/ha) e evilhaca (4.771 kg de MS/ha).

A espécie que apresentou maior produção no espaçamento de $15 \times 3$ m (30\% de restrição de irradiância) foi o azevém (3.478 kg de MS/ha), entretanto não diferiu da aveia-branca, trigo duplo propósito e ervilhaca, portanto foram menos influenciados pela restrição. A espécie que menos produziu nessas condições foi a aveia-preta (1.963 kg MS/ha).

No espaçamento de $9 \times 3 \mathrm{~m}(60 \%$ de restrição de irradiância), a espécie que apresentou maior produção foi o azevém $(1.814 \mathrm{~kg}$ de $\mathrm{MS} / \mathrm{ha})$, que não diferiu $(\mathrm{P}>0,05)$ do trigo duplo propósito (1.300 kg de MS/ha) e ervilhaca (1.292 kg de MS/ha). A forrageira que apresentou menor produção neste espaçamento foi a aveia-preta (369 kg de MS/ha), seguida da aveia-branca (974 kg de MS/ha). Essa produção parece insuficiente para propósitos de produção animal ou para fitomassa e ciclagem de nutrientes.

Os resultados confirmam outros trabalhos, como de Peri et al. (2007), que concluíram que a produção de forragem de Dactylis glomerata L. em condições de $100 \%$ e $24 \%$ de disponibilidade de radiação fotossinteticamente ativa diária em plantio de Pinus radiata D. com dez anos foi significativamente afetada pela restrição de luz. Esses autores observaram produção de $8.200 \mathrm{~kg}$ de MS/ha a céu aberto e de $3.800 \mathrm{~kg}$ de $\mathrm{MS} / \mathrm{ha}$ sob sombreamento, que corresponde a $46 \%$ do rendimento obtido a céu aberto. As consequências da restrição da irradiância nas plantas diferem entre espécies. A Dactylis glomerata L. apresentou menor redução da produção, mesmo submetida a condições de pouca luz disponível (24\% de irradiância). Neste trabalho, a produção relativa média das espécies estudadas foi de 19\%, mesmo com 40\% irradiância disponível.

Tabela 2 - Produção de matéria seca (kg/ha) de forrageiras anuais de inverno em três níveis de luminosidade

\begin{tabular}{|c|c|c|c|c|}
\hline \multirow[t]{2}{*}{ Espécie } & \multicolumn{3}{|c|}{ Nível de luminosidade } & \multirow[t]{2}{*}{ Média } \\
\hline & Céu aberto & $15 \times 3 \mathrm{~m}$ & $9 \times 3 \mathrm{~m}$ & \\
\hline Aveia-preta & $4.550 \mathrm{aC}(100 \%)$ & $1.963 \mathrm{bB}(43 \%)$ & 369cC (8\%) & 2294 \\
\hline Aveia-branca & 7.815аАВ (100\%) & $2.808 \mathrm{bAB}(38 \%)$ & 974bB (13\%) & 3.865 \\
\hline Azevém & 8.191aA (100\%) & $3.478 \mathrm{bA} \quad(43 \%)$ & $1.814 \mathrm{cA}(22 \%)$ & 4.494 \\
\hline Trigo duplo propósito & 5.147aBC (100\%) & $2.393 \mathrm{bAB}(46 \%)$ & $1.300 \mathrm{bAB}(25 \%)$ & 2.947 \\
\hline Ervilhaca & $4.771 \mathrm{aC}(100 \%)$ & $2.300 \mathrm{bAB}(48 \%)$ & 1.292bAB (27\%) & 2.788 \\
\hline Média & $6.095(100 \%)$ & $2.595(43 \%)$ & $1.150(19 \%)$ & \\
\hline
\end{tabular}

Médias seguidas de letras minúsculas diferentes nas linhas diferem $(\mathrm{P}<0,05)$ pelo teste Tukey.

Médias seguidas de letras maiúsculas diferentes na coluna diferem $(\mathrm{P}<0,05)$ pelo teste Tukey. 
O rendimento relativo de matéria seca, variável usada para determinação da tolerância ao sombreamento, diminuiu com a redução da luminosidade. No nível de $15 \times 3 \mathrm{~m}$, a produção foi de $43 \%$ do rendimento do céu aberto, diferença que não confirma os resultados descritos por Sartor et al. (2006), que obtiveram rendimentos relativos maiores, neste mesmo local, de 37 e 56\%, com os genótipos de aveia-preta, aveia-branca e azevém-comum, respectivamente. Esta pesquisa foi realizada em condições climáticas bastante favoráveis, com precipitações regulares (1.068 mm entre abril e outubro de 2007). Já o ano de 2006 (Sartor et al., 2006) foi o ano com menor volume pluviométrico dos últimos 16 anos (436 mm no período estudo). Essas condições de restrição hídrica (ano de 2006), baixa umidade e temperaturas elevadas que ocorreram a pleno sol não foram tão pronunciadas no sub-bosque. Nessas situações, ocorre grande vantagem para as plantas que se encontram parcialmente sombreadas.

A espécie que apresentou maior produção relativa no espaçamento de $9 \times 3 \mathrm{~m}$ foi a ervilhaca, com produção de $27 \%$. Ainda nesse espaçamento, o trigo duplo propósito apresentou produção relativa de 25\%; o azevém, de 22\%; e a aveia-branca, de $13 \%$ da produção obtida a céu aberto. A produção relativa da aveia-preta foi a menor, com $8 \%$ da produção a céu aberto, o que comprova sua baixa adaptabilidade ao sombreamento. Esses resultados são diferentes dos encontrados por Barro et al.(2008), que avaliaram as mesmas espécies forrageiras sob o mesmo protocolo experimental e verificaram melhor tolerância ao sombreamento (57\%) da aveia-preta em relação à aveiabranca e ao azevém.

Tendência de produção semelhante foi observada também no nível de sombreamento $15 \times 3 \mathrm{~m}$, no qual as espécies com melhor desempenho relativo foram a ervilhaca, o trigo duplo propósito e o azevém, com 48, 46 e 43\%, respectivamente, da produção obtida a céu aberto. Essas espécies também apresentaram maior produção absoluta, acompanhadas pela aveia-branca, que não diferiu estatisticamente. Essa coincidência não é comum, como no trabalho de Castro (1996), que avaliou espécies de ciclo estival e concluiu que as espécies capim-gordura (Melinis minutiflora Pal. de Bauv.) e capim-setária (Setaria sp.) se adaptaram melhor porque a produção relativa foi menos alterada pela restrição luminosa de $30 \%$. A produção absoluta foi de 3.600 e $5.900 \mathrm{~kg}$ de MS/ha, respectivamente. O capim-andropogon (Andropogon gayanus Kunth), no entanto, nas mesmas condições apresentou queda relativa maior, porém a produção em valores absolutos foi de $9.700 \mathrm{~kg} / \mathrm{h}$ a de MS.

Todos os fatores climáticos têm efeitos significativos sobre a produção e a qualidade das plantas e, neste contexto, a intensidade luminosa influencia de forma indireta a qualidade e de forma direta os processos biológicos, como fotossíntese, respiração, síntese de cloroplastos e de enzimas e outros (Larcher, 2000).

Outra possível explicação para a diferença na produção é a deposição de acículas. Durante o período do experimento, a deposição foi de $270 \mathrm{~kg} / \mathrm{ha}$ de MS de acículas nas entrelinhas do espaçamento $15 \times 3 \mathrm{~m}$ e de $1.034 \mathrm{~kg} / \mathrm{ha} \mathrm{no}$ espaçamento $9 \times 3 \mathrm{~m}$.

A ciclagem dos resíduos vegetais da floresta é um processo biológico de mineralização e imobilização de nutrientes muito dependente da relação carbono:nitrogênio e da composição bioquímica (Boer et al., 2007). Segundo Bonito et al. (2002), uma serrapilheira com elevada relação carbono:nitrogênio proporciona alta retenção de nitrogênio pelos organismos responsáveis pela decomposição e isso reduz a disponibilidade de nitrogênio no solo. A taxa de decomposição dos resíduos vegetais depende diretamente da presença de atividade microbiana, de fungos e actinomicetos, além de decompositores que auxiliam no processo de ciclagem, como besouros e minhocas. Fatores que interferem na velocidade de decomposição são a presença de altos teores de resina, lignina da parede celular das acículas e elevada relação carbono:nitrogênio. O tempo médio de residência da serrapilheira composta por 90\% de acículas é de 3,5 anos (Boer et al., 2007). Portanto, a presença desses resíduos culturais e a necessidade de decomposição podem ter competido por nutrientes. Assim, a maior produção de acículas nos menores espaçamentos arbóreos poderia estar prejudicando a produção de matéria seca das plantas forrageiras por dois mecanismos: o aumento do sequestro de nitrogênio do solo para sua decomposição e possível deficiência desse elemento para as plantas; e a interceptação da já escassa radiação que chega nas plantas pela deposição de acículas sobre o dossel forrageiro. Neste trabalho, no entanto, não se buscou identificar a real influência das acículas sobre a produção vegetal.

Houve interação significativa $(\mathrm{P}<0,05)$ nos teores de proteína bruta (PB) e fibra em detergente neutro (FDN) e relação lâmina foliar:colmo (Tabela 3) entre as espécies e os níveis de luminosidade.

Os resultados obtidos com o trigo duplo propósito foram opostos aos das demais gramíneas, uma vez que o maior teor de proteína bruta foi observado a céu aberto. Esse resultado pode ser atribuído à maior relação lâmina:colmo na ausência de sombreamento, que foi de 4,8, ao passo que, no espaçamento de de $9 \times 3$ m entre plantas, foi de 2,9. O desempenho da ervilhaca não diferiu entre os níveis de sombreamento e a média entre todos os níveis de 
Tabela 3 - Teores de proteína bruta e fibra em detergente neutro e relação lâmina:colmo de espécies forrageiras anuais de inverno manejadas em três níveis de luminosidade

\begin{tabular}{|c|c|c|c|c|}
\hline \multirow[t]{2}{*}{ Espécie } & \multicolumn{3}{|c|}{ Nível de luminosidade } & \multirow[t]{2}{*}{ Média } \\
\hline & Céu aberto & $15 \times 3 \mathrm{~m}$ & $9 \times 3 \mathrm{~m}$ & \\
\hline & \multicolumn{3}{|c|}{ Proteína bruta (\% MS) } & \\
\hline Aveia-preta & $19,9 \mathrm{bB}$ & 20,9abB & $22,4 \mathrm{aA}$ & 21,1 \\
\hline Aveia-branca & $18,4 \mathrm{bC}$ & $19,9 \mathrm{aBC}$ & $20,3 a \mathrm{~B}$ & 19,5 \\
\hline Azevém & $16,7 \mathrm{bD}$ & $17,9 \mathrm{abD}$ & $18,8 \mathrm{aB}$ & 17,8 \\
\hline Trigo duplo propósito & 22,0 aA & $18,8 \mathrm{bCD}$ & $19,4 \mathrm{bB}$ & 20,0 \\
\hline Ervilhaca & $22,3 \mathrm{aA}$ & $23,5 \mathrm{aA}$ & $22,8 \mathrm{aA}$ & 22,8 \\
\hline \multirow[t]{2}{*}{ Média } & 19,8 & 20,2 & 20,7 & \\
\hline & \multicolumn{4}{|c|}{ Fibra em detergente neutro (\% MS) } \\
\hline Aveia-preta & $49,4 \mathrm{c} A \mathrm{~B}$ & $50,6 \mathrm{bB}$ & $53,9 \mathrm{aA}$ & 50,6 \\
\hline Aveia-branca & $47,6 \mathrm{aBC}$ & $44,4 \mathrm{aC}$ & $46,3 \mathrm{aB}$ & 46,1 \\
\hline Azevém & $51,3 \mathrm{aA}$ & $53,8 \mathrm{aA}$ & $52,7 \mathrm{aA}$ & 52,6 \\
\hline Trigo duplo propóito & $45,9 \mathrm{bC}$ & $52,1 \mathrm{aAB}$ & $53,6 \mathrm{aA}$ & 50,5 \\
\hline Ervilhaca & $42,6 \mathrm{aD}$ & $42,0 \mathrm{aC}$ & $42,7 \mathrm{aC}$ & 42,4 \\
\hline \multirow[t]{2}{*}{ Média } & 47,4 & 48,6 & 49,4 & \\
\hline & \multicolumn{3}{|c|}{ Relação lâmina:colmo } & \\
\hline Aveia-preta & $2,0 \mathrm{aB}$ & $1,9 \mathrm{aB}$ & $2,5 \mathrm{aB}$ & 2,1 \\
\hline Aveia-branca & $3,7 \mathrm{aA}$ & $3,9 \mathrm{aA}$ & $6,2 \mathrm{aA}$ & 4,6 \\
\hline Azevém & $1,6 \mathrm{bB}$ & 2,2abB & $3,4 \mathrm{aAB}$ & 2,4 \\
\hline Trigo duplo propósito & $4,8 \mathrm{aA}$ & $2,2 \mathrm{bB}$ & $2,9 \mathrm{bB}$ & 3,3 \\
\hline Média & 3,0 & 2,5 & 3,7 & \\
\hline
\end{tabular}

Médias seguidas de letras minúsculas diferentes, nas linhas, diferem $(\mathrm{P}<0,05)$ pelo teste Tukey.

Médias seguidas de letras maiúsculas diferentes na coluna diferem $(\mathrm{P}<0,05)$ pelo teste Tukey.

sombreamento foi de $22,8 \%$ de proteína bruta, superando todas demais espécies. O azevém apresentou o menor teor de proteína bruta, com valor de 17,8\%, que é inferior ao apresentado por todas as demais gramíneas avaliadas, aveia-preta, trigo duplo propósito e aveia-branca, com 21,1; 20 e $19,5 \%$, respectivamente.

Os resultados deste estudo não confirmam os obtidos por Barro et al. (2008), que avaliaram a composição química de forrageiras de ciclo hibernal sob diferentes níveis de luminosidade no Rio Grande do Sul e concluíram que o azevém foi superior, com 14,9\% de proteína bruta, e diferiu estatisticamente da aveia-branca e aveia-preta com 11,8 e 10,7\%, respectivamente. As variações e pequenas diferenças são admissíveis, pois os trabalhos foram realizados em situações com diferenças de ecossistemas, épocas, genética das plantas, de espaçamentos e condições edafoclimáticas, fatores que são de difícil controle local.

As diferenças de produção e composição química entre espécies são esperadas, pois as adaptações evolutivas em relação às condições de radiação fazem parte do genótipo e determinam os lugares preferenciais de diferentes espécies e dos fotoecotipos (Larcher, 2000). A maioria das espécies, sob restrição da luminosidade, apresenta aumento do teor de proteína bruta (Garcez Neto et al., 2010; Paciullo et al., 2007). As principais hipóteses relacionadas ao aumento de conteúdo protéico são creditadas às boas condições de mineralização da matéria orgânica proporcionada pelas boas condições térmicas e hídricas do ambiente sombreado e tamanho menor das células. No presente estudo o aumento do teor de proteína bruta, também pode ser creditado a maior relação lâmina:colmo que ocorreu na sombra.

Em pesquisa realizada por Burner \& Belesky (2004) com Dactylis glomerata L, cultivada em sistema silvicultural, a conclusão foi que em ambientes sombreados ocorre um incremento na proteína bruta de 27 a 33\%; 1 a $2 \%$ da digestibilidade; o rendimento de produção de matéria seca diminuiu entre 28 a 34\% e houve redução entre 27 a 34\% de carboidratos não estruturais. Segundo Ribaski et al. (1998) a redução da fotossíntese no sombreamento causa uma maior eficiência de conversão da energia solar em energia química. Ocorre também uma elevação de clorofila, aumento do $\mathrm{N}$ e incremento da área foliar, que contribuem com o aumento da proteína bruta. Porém, as diferenças dos teores de proteína bruta entre os níveis de luminosidade na estação seca são diferentes dos registrados na época de chuvas, como Carvalho et al. (1999) observaram em um experimento com Brachiaria decumbens. Na época de seca os teores de proteína bruta aumentaram em $80 \%$ nas áreas sob copas das árvores de acácia (Acacia sp.) em relação ao sol pleno, no sudeste brasileiro. Na época das chuvas este aumento foi de $20 \%$. Ocorreu uma melhoria nos teores de proteína bruta nas parcelas a céu aberto no período de chuvas. Barro et al. (2008), no Rio Grande do Sul, observaram diferenças nas respostas entre dois anos. Em 2005 não constataram diferença significativa no teor de proteína bruta, entre os diferentes níveis de sombreamento em sistema com $P$. elliottii, no cultivo de azevém, aveiabranca e aveia-preta. Em 2006, em condições de sombra fraca apresentou maior teor de proteína bruta $(9,9 \%)$ em relação ao teor proteico das plantas a pleno sol (8,9\%).

Os teores de fibra em detergente neutro da aveiapreta e trigo duplo propósito foram mais elevados nos locais de maior restrição de luz. A aveia-preta, azevém e ervilhaca não diferiram estatisticamente nos três níveis de restrição de luminosidade. O azevém foi uma das espécies forrageiras de maior teor de fibra em detergente neutro nos três níveis de sombreamento e a ervilhaca, a que apresentou menores teores de fibra em detergente neutro em todos os níveis.

Carvalho et al. (1999) estudaram o efeito do sombreamento na produção de Brachiaria decumbens e não constataram diferenças significativas nos teores de fibra em detergente neutro entre os resultados obtidos com e sem sombra. Entretanto, há relatos como de Carvalho (2001) de que as forrageiras apresentam tendências de menores teores de fibra em detergente neutro e maior digestibilidade 
in vitro quando sombreadas. Existem trabalhos com resultados bastante controversos: Gobbi et al. (2009), igualmente, estudaram a Brachiaria decumbens e concluíram que o sombreamento crescente não causou alterações significativas nos constituintes da parede celular no primeiro corte. As plantas no segundo corte, no entanto, apresentaram queda linear dos conteúdos de fibra em detergente neutro e fibra em detergente ácido (FDA), com aumento de sombreamento. No terceiro corte, apenas os teores de fibra em detergente ácido aumentaram com o sombreamento. Sobre os teores de fibra em detergente neutro, a maioria dos relatos descreve diminuição em ambientes mais sombreados. No entanto, Lin et al. (2001) observaram tanto aumentos como reduções pequenas em certas espécies, assim como não observaram alterações em outras. De acordo com esses autores, quando ocorre aumento da parede celular sob sombreamento, há também redução da porcentagem de carboidratos não-fibrosos como amido e açúcares solúveis. Em virtude dessa variabilidade de respostas, é possível que a grande causa dessas diferenças seja a capacidade de adaptação do funcionamento do aparato fotossintético à restrição luminosa. Nas plantas sob sombreamento, ocorrem alterações morfofisiológicas, como a presença de mais água nos tecidos e maior volume de tecido citoplasmático em comparação ao tecido da parede celular; menor quantidade de tecido de sustentação e de condução de nutrientes; a relação entre clorofila $a$ e clorofila $b$, é menor; há menor quantidade de cloroplastos, mas com tamanho superior; os estômatos são maiores, porém apresentam menor densidade; as folhas são mais finas e estreitas; tem uma relação área da folha:peso da folha maior; têm maior eficiência fotossintética e se saturam sob baixa irradiância (Berlyn \& Cho, 2000). Samarakoon et al. (1990) verificaram efeito negativo da sombra sobre a digestibilidade das plantas e citaram como causas o maior teor de sílica e lignina, a acentuada elongação do colmo, o menor perfilhamento e a menor digestibilidade da parede celular.

A relação de lâmina:colmo é importante indicador estrutural das forrageiras, pois, quanto maior a proporção de folhas, maior o valor nutritivo da pastagem.

Entre as espécies avaliadas, aveia-preta e aveia-branca não diferiram $(\mathrm{P}>0,05)$ entre os níveis de luminosidade. $\mathrm{O}$ azevém, no entanto, teve maior proporção de folhas na sombra e o trigo duplo propósito maior proporção de folhas a céu aberto. O efeito da elevada relação lâmina:colmo do trigo duplo propósito $(4,8)$ revelou-se nos altos de proteína bruta. Uma das causas dessa elevada relação pode ser fato de o trigo duplo propósito ter intenso perfilhamento e período mais prolongado de emissão de folhas, apesar da dependência extrema de maiores níveis de irradiância.

A aveia-branca, em todos os níveis de irradiância, apresentou a maior relação lâmina:colmo, independentemente do nível de luminosidade; a aveia-preta e o azevém, relações intermediárias, embora no espaçamento $9 \times 3 \mathrm{~m}$, o azevém não tenha diferido da aveia-branca. O trigo duplo propósito, como mencionado anteriormente apresentou alta relação lâmina:colmo a pleno sol e diminuiu a relação quando sombreado. A média de todas as espécies foi de 3,7, ao nível de $9 \times 3$, sendo superior aos demais níveis de irradiância.

As respostas aos níveis de sombreamento, segundo Lin et al. (2001), também diferiram entre as espécies forrageiras. Entretanto, Gobbi et al. (2009) estudaram a Brachiaria decumbens sob os níveis de 0, 50 e 70\% de sombreamento e concluíram que não houve efeito do sombreamento sobre a relação lâmina:colmo.

As plantas que se adaptam em ambientes de radiação fraca têm colmos mais finos, produzem entrenós longos e folhas delgadas e mais amplas, com grande superfície, assim, podem sobreviver em lugares com pouca radiação (Larcher, 2000). Isso pode justificar os resultados obtidos neste estudo. Garcez Neto et al. (2010) publicaram resultados obtidos na Nova Zelândia, em que mediram a interceptação luminosa pelo dossel das forrageiras Dactilys sp., azevém e trevo-vermelho e relataram que, em ambiente com 75\% restrição luminosa, Dactilys sp. intercepta a radiação com tanta eficiência quanto o azevém e o trevo em ambientes com 50 e $25 \%$ de restrição, respectivamente. Isso proporcionou, de acordo com os autores, índice de área foliar mais abundante em ambientes mais sombreados.

O resultado da relação entre redução da luminosidade e composição química parece que não é muito clássico, como ocorre com a produção de matéria seca. $\mathrm{Na}$ investigação, é importante considerar sobremaneira as condições em que são feitos os estudos, inclusive tipo solo, umidade do ar e do solo, temperatura do solo e ar, sentido do plantio do componente arbóreo, idade e altura do componente arbóreo e métodos de avaliação.

As avaliações de potencial hídrico ( $\psi w$ w) (Tabela 4) foram feitas a partir das 6 h e $12 \mathrm{~h}$ para verificar a influência dos três níveis de luminosidade no potencial hídrico de duas espécies leguminosas (ervilhaca e trevo-branco). Foram encontradas diferenças significativas $(\mathrm{P}<0,05)$ entre os níveis de luminosidade nas duas leguminosas avaliadas. O maior potencial hídrico das plantas sombreadas, especialmente nas horas mais quentes do dia, é indicativo da diminuição da evapotranspiração das plantas e, aliado à 
Tabela 4 - Potencial hídrico médio em plantas de trevo-branco e ervilhaca manejadas em três níveis de luminosidade

\begin{tabular}{lcc}
\hline Nível de sombreamento & $\psi \mathrm{w}(\mathrm{MPa})-12 \mathrm{~h}$ & $\psi \mathrm{w}(\mathrm{MPa})-6 \mathrm{~h}$ \\
\hline Céu aberto & $1,013 \mathrm{a}$ & $0,287 \mathrm{a}$ \\
$15 \times 3 \mathrm{~m}$ & $0,467 \mathrm{~b}$ & $0,24 \mathrm{ab}$ \\
$9 \times 3 \mathrm{~m}$ & $0,458 \mathrm{~b}$ & $0,2255 \mathrm{~b} *$ \\
\hline
\end{tabular}

Médias seguidas de letras minúsculas diferentes na coluna diferem $(\mathrm{P}<0,05)$ pelo teste Tukey.

maior umidade do solo em ambientes sombreados, conferem às plantas maior tolerância às estiagens, como discutido anteriormente.

Embora o inverno tenha sido de precipitações regulares e temperaturas bastante amenas, verificou-se clara tendência de queda do potencial hídrico das plantas avaliadas ao nível céu aberto. O $\psi$ w ao meio dia foi de 1,013 MPa. As plantas passam a ter limitações na síntese de proteínas, síntese de parede e expansão celular a partir de $\psi$ w de 0,9 MPa. A redução do potencial hídrico na folha no decorrer do dia está relacionada ao aumento da taxa de transpiração, principalmente entre as 12 e as $14 \mathrm{~h}$, e, quando em condições extremas, geralmente as plantas são submetidas ao estresse hídrico (Taiz \& Zeiger, 2004).

\section{Conclusões}

Entre as espécies avaliadas, a ervilhaca, o trigo duplo propósito e o azevém são as mais adaptadas ao sombreamento, porém o sombreamento mais intenso reduz $81 \%$ a produção de forragem das espécies forrageiras, que não compensada pelo maior teor de umidade, nem das plantas nem do solo, nos ambientes sombreados. Na maioria dessas espécies, ocorre aumento dos teores de proteína bruta e fibra em detergente neutro na presença de sombreamento, mas não há diferença significativa na relação lâmina:colmo entre os níveis de sombreamento.

\section{Agradecimentos}

À empresa CAMIFRA de Clevelândia, que gentilmente cedeu suas instalações e proporcionou a equipe de trabalho realizar a pesquisa em sua propriedade. A EMBRAPA pelo apoio com recursos financeiros e humanos, ao IAPAR na realização de levantamento de dados micro-climáticos.

\section{Referências}

ANDRADE, M.S.A.; GARCIA, R.; COUTO, L. et al. Desempenho de seis gramíneas solteiras ou consorciadas com o Stylosanthes guianensis cv. Mineirão e Eucalipto em sistema silvipastoril. Revista Brasileira de Zootecnia, v.32, n.6, p.1845-1850, 2003 (supl. 2).
BARRO, R.S.; SAIBRO, J.C.; MEDEIROS, R.B. et al. Rendimento de forragem e valor nutritivo de gramíneas anuais de estação fria submetidas a sombreamento por Pinis elliottii e ao sol pleno. Revista Brasileira de Zootecnia, v.37, n.10, p.1721-1727, 2008.

BERLYN, G.P.; CHO, J. Light, moisture, and nutrient use by plants. In: ASHTON, M.S.; MONTAGNini, F. (Eds.). The silvicultural basis for agroforestry systems. Boca Raton: CRC Press, 2000. p.9-39.

BIRCHAM, J.S. Herbage growth and utilization under continuous stocking management. 1981. 384f. Thesis (Ph.D in Computer Science) - University of Edinburgh, Edinburgh.

BOER, A.C.; ASSIS, R.L.; SILVA, G.P. et al. Ciclagem de nutrientes por plantas de cobertura na entressafra em um solo de cerrado. Pesquisa Agropecuária Brasileira, v.42, n.9, p.1269-1276, 2007.

BONITO, G.M.; COLEMAN, D.C.; HAINES, B.L. et at. Can nitrogen budgets explain differences in soil nitrogen mineralization rates of forest stands along an elevation gradient? Forest Ecology and Management, v.5991, p.1-12, 2002.

BURNER, D.; BELESKY, D. Diurnal effects on nutritive value of Alley Cropped orchardgrass herbage. In: World Congress of agroforestry: working together for sustainable land use systems, 1. 2004, Orlando. Book of abstracts... University of Florida, 2004. p.171.

CARVALHO, M.M. Contribuição dos sistemas silvipastoris para a sustentabilidade da atividade leiteira. In: SIMPÓSIO SOBRE A SUSTENTABILIDADE DE SISTEMAS DE PRODUÇÃO DE LEITE A PASTA E EM CONFINAMENTO, 1., 2001, Juiz de Fora. Anais... Juiz de Fora: EMBRAPA Gado de Leite, 2001. p.85-108.

CARVALHO, M.M.; BARROS, J.C.; XAVIER, D.F. et al. [1999]. Composición quimica del forraje de Brachiaria decumbens asociada con tres especies de leguminosas arboreas. Disponível em: <http://www.cipav.org.co/redagrofor/>Acesso em: $6 / 10 / 2008$

CASTILHOS, Z.M.S.; SAVIAN, J.F.; SANTOS, E.M. et al. Sistema silvipastoril com acácia negra (Acacia mearnsii): desempenho dos componentes arbóreo e animal. In: CONGRESSO FLORESTAL ESTADUAL DO RIO GRANDE DO SUL, 9. 2003, Nova Prata. Resumos... Nova Prata, [2003]. (CD-ROM).

CASTRO, C.R.T. Tolerância de gramíneas forrageiras tropicais ao sombreamento. 1996. 247f. Tese (Doutorado em Zootecnia) - Universidade Federal de Viçosa, Viçosa, MG.

COMISSÃO DE FERTILIDADE DO SOLO - RS/SC. Manual de adubação e de calagem para os Estados do Rio Grande do Sul e Santa Catarina. Porto Alegre: Sociedade Brasileira de Ciência do Solo, 2004. 394p.

DIFANTE, G.S.; NASCIMENTO JR., D. [2003]. Importância da morfogênese no manejo de gramíneas forrageiras. Viçosa, MG: DZO - Universidade Federal de Viçosa, 2003. Disponível em: <www.forragicultura.com.br> Acesso em: 06/10/2008.

EMPRESA BRASILEIRA DE PESQUISA AGROPECUÁRIA EMBRAPA. Centro Nacional de Pesquisas de solos. Rio de Janeiro. Sistema Brasileiro de Classificação dos solos. Rio de Janeiro: Embrapa/CNPS, 1999. 412p.

GARCEZ NETO, A.F.; GARCIA, R.; MOOT, D.J. et al. Aclimatação morfológica de forrageiras temperadas a padrões e níveis de sombreamento. Revista Brasileira de Zootecnia, v.39, n.1, p.42-50, 2010

GARCIA, R.; BERNARDINO, F.S.; GARCEZ NETO, A.F. Sistemas Silvipastoris. In: EVANGELISTA, A.R.; AMARAL, P.N.C.; PADOVANI, R.F. et al. (Orgs.) Forragicultura e pastagens temas em evidência. Lavras: Editora UFLA, 2005. p.1-64.

GOBBI, K.F.; GARCIA, R.; VENTRELLA, M.C. et al. Características morfológicas, estruturais e produtividade do capim-braquiária e do amendoim forrageiro submetidos ao 
sombreamento. Revista Brasileira de Zootecnia, v.38, n.9, p.1645-1654, 2009.

LARCHER, W. Ecofisiologia vegetal. Tradução: Carlos Henrique B. A. Prado. São Carlos: Rima Editora, 2000. 531p.

LIN, C.H.; MCGRAW, R.L.; GEORGE, M.F. et al. Nutritive quality and morphological devolpment under partial shade of some forages species with agorforestry potencial. Agroforestry Systems, v.59, p.269-281, 2001.

MORENO, J.A. Clima do Rio Grande do Sul. Porto Alegre: Secretaria da Agricultura, 1961. 41p.

PACIULLO, D.S.C.; CARVALHO, C.A.B.; AROEIRA, L.J.M. et al. Morfologia e valor nutritivo de capim-braquiária sob sombreamento natural e a pleno sol. Pesquisa Agropecuária Brasileira, v.42, n.4, p.573-579, 2007.

PERI, P.L.; LUCAS, R.J.; MOOT, D.J. Dry Matter production, morphology and nutritive value of Dactylis glomerata growing under different light regimes. Agroforestry Systems Jounal, v.70, n.1, p.63-79, 2007.

RIBASKI, J.; INOUE, M.G.; LIMA FILHO, J.M.P. Influência da algaroba (Prosopis juliflora) sobre alguns parâmetros ecosfisiológicos e seus efeitos na qualidade de uma pastagem de capim buffel (Cenchrus ciliaris L.), na região semi-árida do Brasil. In: CONGRESSO BRASILEIRO EM SISTEMAS AGroflorestais, 2., 1998, Belém. Anais... Belém: EMBRAPA - CPATU, 1998. p.219-220.

SAMARAKOON, S.P.; WILSON, J.R.; SHELTON, H.M. Growth, morphology and nutritive quality of schaded Stenotaphrum secundatum, Axonopus compressus and Pennisetum clandestinum. Journal of Agricultural Science, v.114, p.161-169, 1990.

SARTOR, L.R.; SOARES, A.B.; ADAMI, P. et al. Produção de forragem de espécies de inverno em ambiente sombreado. Revista Synergismus Scyentifica, v.1, n.1, p.13-21, 2006.

SILVA, V.P.; VIEIRA, A.R.R.; BAGIO, A.J. et al. Sombras e ventos em sistema silvipastoril no noroeste do estado do Paraná. In: CONGRESSO BRASILEIRO EM SISTEMAS AGROFLORESTAIS, 2., 1998, Belém. Anais... Belém: EMBRAPA, 1998. p.215-218.

TAIZ, L.; ZEIGER, E. Fisiologia vegetal. Tradução: Santarém, E.S. et al. 3.ed. Porto Alegre: Artmed. 2004. 719p. 